\title{
CORROSION OF CARBON SUPPORTS, INDUCED BY HIGH-TEMPERATURE PEMFC OPERATING CONDITIONS
}

\author{
María Rau $^{(1)}$, Florina Jung ${ }^{(1)}$, Carsten Cremers ${ }^{(1)}$, Jens Tübke $^{(1)}$ \\ (1) Fraunhofer Institute for Chemical Technology ICT, Joseph-von-Fraunhofer-Str. 7, 76327 Pfinztal, Germany, \\ E-mail: jens.tübke@ict.fraunhofer.de
}

\begin{abstract}
In high-temperature polymer electrolyte membrane fuel cells (HT-PEMFC) one of the detrimental factors that lead to loss of performance is the corrosion of the electrocatalyst support. In both anode and cathode, platinum $(\mathrm{Pt})$ supported on carbon is generally the selected electrocatalyst. Platinum significantly increases the speed of the anode and cathode reactions, but also causes carbon oxidation (corrosion of the support) and the consequent degradation of the electrode materials. In a HT-PEMFC, corrosion is influenced by temperature. For this reason, this paper will present a detailed evaluation of the carbon support degradation under HTPEMFC conditions. The carbon oxidation of two types of carbon supports will be compared.
\end{abstract}

\section{INTRODUCTION}

High-temperature polymer electrolyte membrane fuel cells (HT-PEMFCs) are considered very promising electrochemical devices for the production of energy from hydrogen. Due to the range of operating temperatures (between $120^{\circ} \mathrm{C}$ and $180^{\circ} \mathrm{C}$ ) the electroadsorption of $\mathrm{CO}$ in the active surface is significantly reduced in this type of fuel cell, which reduces the negative effects of $\mathrm{CO}$ in the electrodes [1]. Another advantage of HT-PEMFCs is that they allow the co-generation of cooling, heat and power (CHP) for auxiliary power unit applications [2]. However, a high efficiency of these electrochemical devices requires a higher stability of both electrodes (anode and cathode). One of the damaging factors which play a role in the decay of electrocatalytic activity of the Pt supported on carbon $(\mathrm{Pt} / \mathrm{C})$ electrodes used in fuel cells is the corrosion of the carbon support. The influence of several factors, including the electrode fabrication parameters (Teflon content and sintering temperature) has been determined [3]. Electrochemical measurements carried out at $160^{\circ} \mathrm{C}$ for phosphoric acid fuel cells (PAFC) in the potential range between $0.6 \mathrm{~V}$ (vs. RHE) and $1.0 \mathrm{~V}$ (vs. RHE) indicate that the corrosion rate increases with an increase in Pt content, and is most noticeable at $0.6 \mathrm{~V}$. These results show the strong influence of the presence of the supported metal on the extent of carbon corrosion under real conditions [4]. Moreover the influence of $\mathrm{Pt}$ activation on the corrosion of carbon in gas diffusion electrodes was investigated using differential electrochemical mass spectroscopy [5].

In a HT-PEMFC a phosphoric-acid-doped polybenzylimidazole (PBI) membrane for the ionic exchange of protons has been demonstrated to be the most successful electrolyte system for high-temperature operation [6]. Considering this, the evaluation of the corrosion of Pt-based electrocatalysts in two different supports under HT-PEMFC conditions in the potential window between $0.0 \mathrm{~V}$ (vs. RHE) and $1.0 \mathrm{~V}$ (vs. RHE) will be evaluated in this paper. A three electrode cell connected to a mass spectrometer [7] was used, which allows the study of a gas diffusion electrode.

\section{EXPERIMENTAL PROCEDURE}

Measurements were carried out in a three electrode cell working under HT-PEMFC conditions and connected to a mass spectrometer [7]. The working electrodes tested consisted of homemade $\mathrm{Pt}$ supported on carbon nanotubes $(\mathrm{Pt} / \mathrm{CNT})$ or carbon vulcan $(\mathrm{Pt} / \mathrm{CV})$ and deposited on a GDL H2315 (FREUDENBERG FCCT SE \& CO.KG9). The electrodes had a geometric electrode area of $3 \mathrm{~cm}^{2}$ and platinum loadings of $1.0 \pm$ $0.1 \mathrm{mg}_{\mathrm{Pt}} \mathrm{cm}^{-2} . \mathrm{H}_{3} \mathrm{PO}_{4} 85 \%$ (Carl Roth) was used as electrolyte. A Gaskatel HydroFlex ${ }^{\circledR}$ reversible hydrogen electrode (RHE) in the same medium was used as a reference electrode, and a large area $\mathrm{Pt}$ electrode as counterelectrode. Phosphoric-acid-doped polybenzimidazole (PBI) membranes were used as the polymer electrolyte membrane. Prior to the evaluation of the electrocatalytic corrosion, the cell was purged with a pure nitrogen flow, which was continued during the entire measurement procedure in order to maintain the electrode in an inert atmosphere. Under these conditions both electrodes were characterized through cyclic voltammetry at a potentiodynamic sweep of 10 $\mathrm{mV} / \mathrm{s}$ in $\mathrm{H}_{3} \mathrm{PO}_{4} 85 \%$ at $160^{\circ}$. The electrodes were cycled fifteen times until a stable profile was obtained. The last measurements corresponding to each electrode are presented in Figures 1 and 2.

A sequence of potential steps with a 5 min. duration pro step (time required to obtain the corresponding steady state current) in the range of $0.0 \leq \mathrm{E} / \mathrm{V}$ (vs. RHE) $\leq 1.0$ was then applied to the electrodes (Figure 3). With this procedure, the corrosion of the electrodes operating as an anode (under $0.2 \mathrm{~V}$ vs. RHE) or a cathode (over $0.8 \mathrm{~V}$ 
vs. RHE) under inert conditions was evaluated.

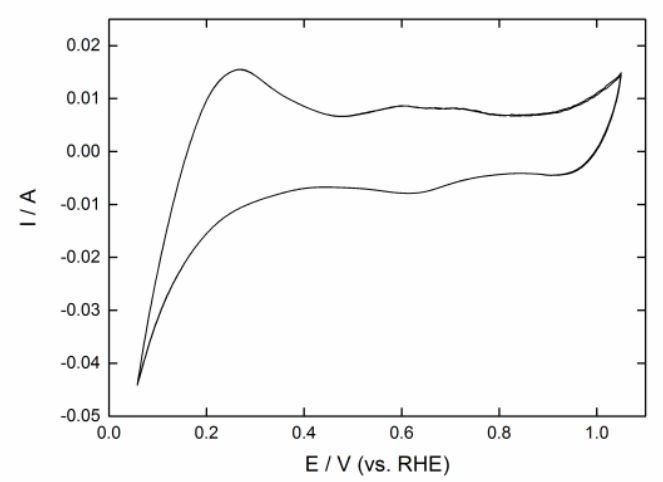

Figure 1. Cyclic voltammetry of Pt/CNT at $10 \mathrm{mV} / \mathrm{s}$ in $\mathrm{H}_{3} \mathrm{PO}_{4} 85 \%$ at $160^{\circ} \mathrm{C}$

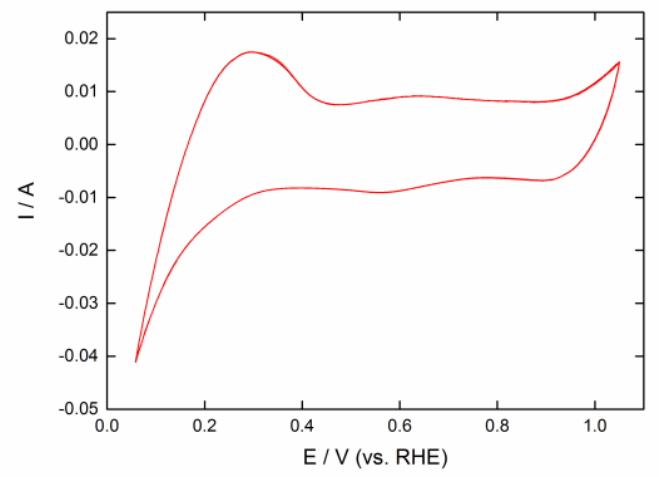

Figure 2. Cyclic voltammetry of $\mathrm{Pt} / \mathrm{CV}$ at $10 \mathrm{mV} / \mathrm{s}$ in $\mathrm{H}_{3} \mathrm{PO}_{4} 85 \%$ at $160^{\circ} \mathrm{C}$

Figure 4 shows the dependence of the current on the potential obtained from the evaluation of the applied potential and the measured current. Simultaneously, measurements of the ionic mass 44 , which is related to $\mathrm{CO}_{2}$ formation and carbon corrosion, were obtained with the mass spectrometer (MS) connected on line. The mass spectrometer is a Pfeiffer vacuum system with a Prisma $^{\mathrm{TM}}$ quadrupole analyzer.

Finally, the CVs of the electrodes in $\mathrm{N}_{2}$ were recorded in order to demonstrate the stability of the materials.

\section{RESULTS AND DISCUSSION}

Figure 3 shows the potential program applied and the corresponding current obtained for a $\mathrm{Pt} / \mathrm{CNT}$ (black) and $\mathrm{Pt} / \mathrm{CV}$ (red) electrode with pure $\mathrm{N}_{2}$. Under these conditions, the oxidation of the carbon supports can be attributed to independent processes: hydrogen evolution under $0.2 \mathrm{~V}$ vs. RHE and oxygen evolution over $0.6 \mathrm{~V}$ vs. RHE. It can be observed that for the potential steps under $0.6 \mathrm{~V}$ vs. RHE the currents measured reached a plateau, while for higher potentials a constant decay was noted. This could be due to a massive degradation of the electrocatalyst at these higher potentials, which did not allow the stabilization of the measured current during the acquisition time. From this measurement, the dependence of the current on the potential was obtained (Figure 4). At lower potentials (under $0.2 \mathrm{~V}$ vs. RHE) the measured currents are generated by the evolution of hydrogen. By contrast, at higher potentials (over $0.6 \mathrm{~V}$ vs. RHE) the current measured is due to oxygen evolution. From the comparison of the current dependences illustrated in Figure 4, the same dependence of the current on the potential was observed but for $\mathrm{Pt} / \mathrm{CV}$ the currents for potentials over $0.5 \mathrm{~V}$ vs. RHE were slightly higher than for $\mathrm{Pt} / \mathrm{CNT}$. A possible cause could be that a larger area of activated $\mathrm{Pt}$ was exposed on the electrode supported on carbon vulcan.

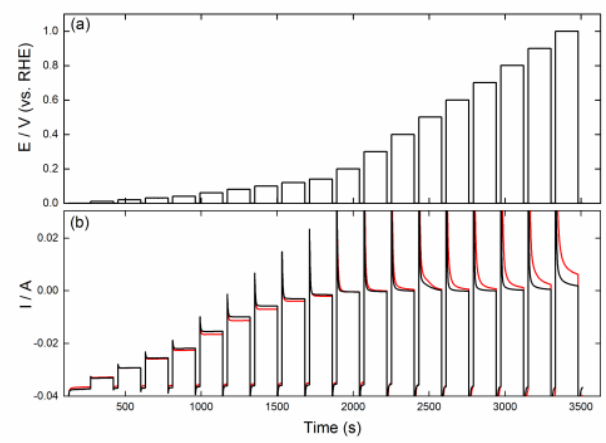

Figure 3. (a) Sequence of potential steps (a) applied for the evaluation of the carbon corrosion, (b) measured currents for Pt/CNT (black) and Pt/CV (red).

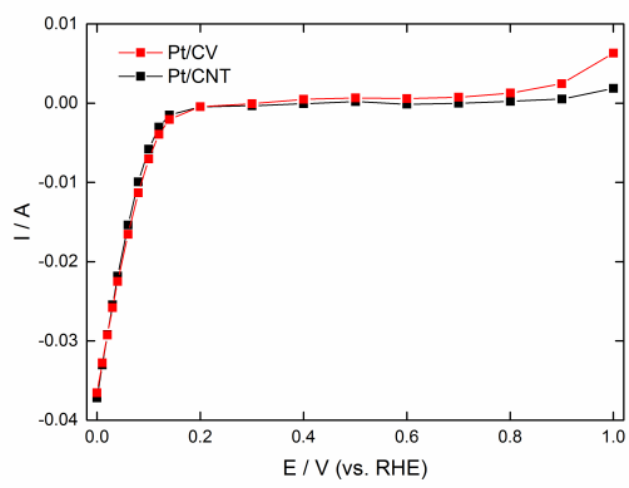

Figure 4. Dependence of the current on the potential for $\mathrm{Pt} / \mathrm{CNT}$ (black) and Pt/CV (red).

In parallel to the electrochemical measurements (Figures 3 and 4), the ionic mass current for mass 44 (associated with $\mathrm{CO}_{2}$ ) was recorded by a mass spectrometer connected to the three electrode cell. The dependence of the ionic mass currents for mass 44 on the potential, measured during the application of the potential steps (Figure 3), is illustrated in Figure 5. Here it can be noted that the ionic currents measured for 
$\mathrm{Pt} / \mathrm{CV}$ are four times greater than for $\mathrm{Pt} / \mathrm{CNT}$. These results are in agreement with the experimental investigation on carbon support corrosion rates in lower temperature PEM fuel cells carried out at the Fraunhofer Institute for Chemical Technology ICT under real operating conditions.

In Figure 5 two oxidation domains, represented by a peak in the oxidation ionic current, were determined. One small peak in the carbon corrosion is observed at $0.4 \mathrm{~V}$ vs. RHE for $\mathrm{Pt} / \mathrm{CV}$ and at $0.5 \mathrm{~V}$ vs. RHE for $\mathrm{Pt} / \mathrm{CNT}$. A second oxidation peak was measured for higher potentials: at $0.9 \mathrm{~V}$ vs. RHE for $\mathrm{Pt} / \mathrm{CV}$ and at $1.0 \mathrm{~V}$ vs. RHE for Pt/CNT. It is worth noting that even though these results are in good agreement with the previous observations made by Passalacqua et al. [4], a small difference in the measured potentials of higher corrosion could be related to the use of the PBI membrane, which could generate a displacement in the recorded values.

Figure 5 shows that in the range of potentials lower than $0.2 \mathrm{~V}$ vs. RHE, where the hydrogen oxidation takes place, no significant corrosion of the support (for both materials) was detected under HT-PEMFC conditions. By contrast, at higher potentials over $0.8 \mathrm{~V}$ vs. RHE a higher corrosion was determined. In this context, the higher corrosion of HT-PEMFC cathodes, which operates at higher potentials, is illustrated.

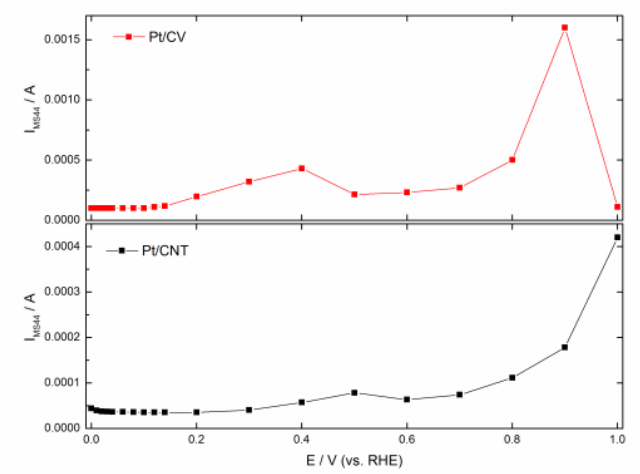

Figure 5. Dependence of the ionic mass current for mass 44 on the potential for Pt/CNT and Pt/CV.

In order to determine the intrinsic corrosion of the carbon support in the absence of platinum, the dependence of the ionic mass current for mass 44 on the potential for a carbon vulcan electrode (without addition of $\mathrm{Pt}$ ) was obtained following the procedure already described for the Pt-containing electrodes. This evaluation is shown in Figure 6. Here it can be noted that for the carbon vulcan $(\mathrm{CV})$ electrode (represented in blue) there is only one peak in the carbon dioxide formation at $0.9 \mathrm{~V}$ vs. RHE and that the measured currents of this peak are in the same order as those of $\mathrm{Pt} / \mathrm{CV}$ (represented in red). These results agree with previous research [4] that proved the massive corrosion observed at potentials higher than $0.9 \mathrm{~V}$ vs. RHE.

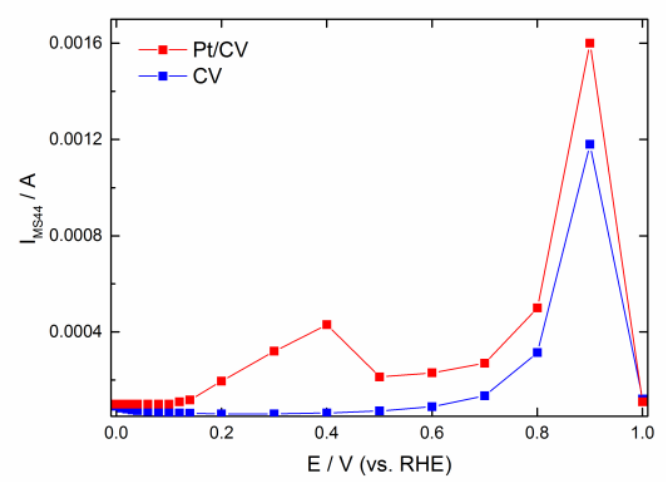

Figure 6. Dependence of the ionic mass current for mass 44 on the potential for Pt/CV (red) and CV (blue).

With this evidence it is possible to confirm that the presence of $\mathrm{Pt}$ in the HT-PEMFC has an important impact on the corrosion of the electrocatalyst support. This is despite of the fact that at potentials over $0.8 \mathrm{~V}$ vs. RHE the corrosion of the carbon support was identified as a common process resulting from the nature of the support and the highly corrosive working conditions of a HT-PEMFC.

In regard to the peak of corrosion observed at $0.4 \mathrm{~V}$ vs. $\mathrm{RHE}$ for $\mathrm{Pt} / \mathrm{CV}$ and at $0.5 \mathrm{~V}$ vs. $\mathrm{RHE}$ for $\mathrm{Pt} / \mathrm{CNT}$, it can be noted that, as the active electrocatalyst is $\mathrm{Pt}$ in both cases, and as this $\mathrm{Pt}$ has the same intrinsic electrocatalytic activity for both electrodes, the difference in the corrosion peak is directly related to the support and the electrode morphology.

\section{CONCLUSION}

In the investigations described, different carbon supports were tested as electrodes used under HTPEMFC operating conditions. It was found that the carbon corrosion currents are significantly smaller for the $\mathrm{Pt} / \mathrm{CNT}$ electrode than for $\mathrm{Pt} / \mathrm{CV}$. Moreover a shift of about $0.1 \mathrm{~V}$ to more oxidative potentials was observed for the corrosion peaks of $\mathrm{Pt} / \mathrm{CNT}$ but only for lower potentials under $0.2 \mathrm{~V}$ vs. RHE. Not significant corrosion of the electrodes was noted. By contrast, for the higher potential range a significant oxidation of the carbon support for both studied materials was observed. These results provide an overview of the support oxidation taking place under inert conditions, where no electrode reaction takes place. In this context the impact of the potentials applied to the electrodes was determined. This provides valuable information while the electrode process is taking place. Moreover, information concerning the stability of the electrode material during the hydrogen evolution can be useful for the further development of Pt-based electrodes for water electrolysis. 


\section{ACKNOWLEDGEMENT}

This work was financially supported by the German Federal Ministry for Economics and by the European Commission through the ERANET+ Electromobility.

\section{REFERENCES}

1. T. J. Schmidt, J. Baurmeister, ECS Trans., 3 (2006) 861 - 869.

2. G. Giacoppo, O. Barbera, A. Carbone, I. Gatto, A. Saccà, R. Pedicini, E. Passalacqua, Int. J.

Hydrogen Energy, 38 (2013) 11619 - 11627.

3. N. Giordano, E. Passalacqua, V. Recupero, M. Vivaldi, E. J. Taylor, G. Wilenski, Elecrrochim. Aacta, 35 (1990) 1411 -1421.

4. E. Passalacqua, . L. Antonuci, M. Vivaldi, A. Patti, V. Antonucci, N. Giordano, K. Kinoshita, Electrochim. Acta, 37 (1992) 2725 - 2730.

5. J. Willsau, J. Heitbaum, J. Electroanal. Chem., 161 (1984) 93-101.

6. R. Kerr, H. R. García, M. T. Romero, C. Terkelsen, H. A. Hjuler, T. Steenberg, ECS Transactions, 64 (2014) 973 - 982.

7. C. Niether, M. S. Rau, C. Cremers, K. Pinkwart, J. Tübke, J. of Electroanal. Chem., 747 (2015) 97 103. 